\title{
"The sky seems heavy with clouds": Arthur S. Eddington and the IAU
}

\author{
Florian Laguens
}

\author{
IPC-Facultés Libres de Philosophie et de Psychologie, Paris, France \\ email: flaguens@ipc-paris.fr
}

\begin{abstract}
This paper addresses the relationships between Arthur S. Eddington, former director of the Cambridge Observatory (1914-1944), with the International Astronomical Union. It is demonstrated that the Union was related to every major moment in Eddington's scientific career. New historical elements are brought forward, in the last section of the paper, to demonstrate Eddington's action in favour of German colleagues during the Second World War.
\end{abstract}

Keywords. Eddington, relativity, scientific cooperation, Adams, Chandrasekhar, Brück, Jehle, World War II.

\section{Introduction to Eddington}

Arthur S. Eddington (1882-1944) certainly was one of the world's most famous astronomers during the interwar period. For thirty years he was the director of the Cambridge Observatory and taught astrophysics at Trinity College. Along with widely acclaimed scientific treatises - e.g. The Mathematical Theory of Relativity (1923) and The Internal Constitution of the Stars (1926) - Eddington published some controversial books such as The Nature of the Physical World (1928) and Relativity Theory of Protons and Electrons (1936). A century ago he played a major role in writing and lecturing about Einstein's theories. Paul Dirac even called him "the fountainhead of relativity" (Dirac 1977, p. 115). He remains well-known for the 1919 eclipse expedition, during which he measured the deflection of a ray of light passing near the Sun (Kennefick 2009, 2012).

\section{Eddington, the 1919 solar eclipse and relativity}

When the Union was officially created in July 1919, Eddington had just been back from the Principe Island where he had taken photographs of the May 29 total eclipse. Unsurprisingly, he was chosen to preside over Standing Committee 1, devoted to Relativity. Eddington's measures indeed contributed a great deal to a wide acceptance of Einstein's theory as a new paradigm. Nevertheless, it cannot be said that general relativity raised enthusiastic reactions as far as physicists were concerned. Its meagre original predictions contrasted with both the great mathematical abilities required to tackle it and the conceptual revolution it entailed. What is more, none of the three canonical tests was a laboratory experiment that could be controlled and reproduced at will. Astronomers tried to put forward a fourth experimental test, but in vain. Eddington being absent, the discussions of Standing Committee 1 during the first General Assembly (GA) in Rome concentrated on the possibility of measuring the deflection of a ray of light grazing Jupiter and of a quantitative evaluation of the advance of the perihelion of its fifth satellite (IAU 1922, p. 157).

Both hypotheses were set aside, the discrepancy in each case being too small to be detected. Taking good note of these lack of experimental opportunities, Standing 
Committee 1 voted itself out during the 1925 GA in Cambridge. There was no need for a Relativity Committee as nothing new was to be expected in that particular field (IAU 1925, p. 13). It is worth highlighting that there has never been a "Commission 1" among the IAU. The "Commission" label seems to have been adopted at the Leiden GA in 1928, as far as the English language is concerned. It was in fact used in the French translation of the IAU statutes as early as 1922 where the English version said "Standing Committee" (IAU 1922, compare p. 220 vs. p. 227).

The vanishing of the Relativity Committee was indeed symptomatic of a more general trend, that lingered until the early '60s. Chandrasekhar's reminiscence is rather striking:

"Indeed, general relativity as a discipline in physics was simply ignored or at any rate neglected benignly in most institutions devoted to its study. As an illustration of this fact I might refer to the circumstance that from 1936, when I joined the faculty of the University of Chicago, to 1961, no courses in general relativity, not even for one single quarter, were given at the University. And the University of Chicago is not atypical." (Chandrasekhar 1979, p. 214).

The GA in Cambridge was also an occasion for the astronomical community to be informed of Walter Adams's success with Sirius B. And Eddington had a lot to do with it, as he had been the one who suggested Adams that a measurement of the non-Doppler redshift of spectral lines may bring promising results if applied to Sirius B (Holberg 2010). In May 1925, Adams had just completed the paper in which he proudly announced:

"The results may be considered, therefore, as affording direct evidence from stellar spectra for the validity of the third test of the theory of general relativity, and for the remarkable densities predicted by Eddington for the dwarf stars" (Adams 1925, p. 387).

Immediately, he sent his forthcoming paper to Eddington, and a brief summary of its conclusions was given in Cambridge to the members of the IAU (NY Times 1925). The following year Eddington stated:

"Prof. Adams has killed two birds with one stone; he has carried out a new test of Einstein's general theory of relativity and he has confirmed our suspicion that matter 2000 times denser than platinum is not only possible, but is actually present in the universe" (Eddington 1926, p. 173).

This achievement may be one reason for the creation, at the end of the 1928 GA in Leiden, of Commission 35 devoted to the constitution of the stars. Eddington was immediately chosen to preside over it.

\section{Eddington and the expanding universe}

During the 1932 GA in Cambridge (Mass.) Eddington delivered the one and only public lecture of the meeting. The selected subject was the expansion of the universe. A couple of years before then the scientific community had discovered about Georges Lemaître's 1927 paper, later translated in the Monthly Notices of the Royal Astronomical Society under the title: "A Homogenous Universe of Constant Mass and Increasing Radius accounting for the Radial Velocity of Extra-galactic Nebulce." Eddington's 1932 lecture took place at the MIT, in the presence of Lemaitre himself. James Stokley, who wrote an account of the event for The New York Times, seems to have been struck by Eddington using a rubber-balloon to illustrate the expansion of the universe and the recession of the galaxies (Stokley 1932). Ultimately, this lecture was itself expanded into a popular book: The Expanding Universe. Eddington endorsed in the early thirties the role he already had 
a decade earlier - at that time with the general relativity theory. He became a promoter. Helge Kragh rightly states:

"With the enthusiastic support of Eddington and de Sitter, the expanding universe became quickly accepted by most specialists, and cosmology experienced a sudden paradigm shift" (Kragh 2003, p. 528).

\section{Eddington and Chandrasekhar}

It can then be claimed that every major moment in Eddington's scientific life was related, one way or another, to the Union. His famous controversy with Chandrasekhar is no exception. The initial point of this well-documented debate can be dated January 11, 1935. Freshly elected a Fellow of Trinity College, young Chandrasekhar wrote down his personal ideas about the evolution of stars and submitted them to his colleagues' appreciation during a monthly meeting of the Royal Astronomical Society. He argued for the existence of a limiting stellar mass and discussed the behaviour of a star going beyond this limit (Chandrasekhar 1934, 1935a,b,c). Eddington immediately replied:

"Dr Chandrasekhar had got this result before, but he has rubbed it in in his last paper; and, when discussing it with him, I felt driven to the conclusion that this was almost a reductio ad absurdum of the relativistic degeneracy formula. [...] I think there should be a law of Nature to prevent a star from behaving in this absurd way!" (Eddington 1935a, p. 38).

A few months later, at the Paris GA, Eddington made the most of the opportunity to mention his reticence about Chandrasekhar's theory in the report of Commission 35:

"The writer has recently contended that the 'relativistic' degeneracy formula extensively used in stellar investigations is unsound and that the 'ordinary' formula is the correct deduction from the relativity and quantum theory. A decision on this point profoundly affects the theory of super-dense stars" (Eddington 1936, p. 238).

\section{Eddington as president of the IAU}

Finally, the director of the Cambridge Observatories was elected president of the Union at the concluding session of the Stockholm GA, on 10 August 1938. To be more specific, he did attend this GA, but he left on the last day in the early morning. He had to travel back to England and make the final preparations for the annual meeting of the British Association that was to begin on 17 August in Cambridge. Therefore, he was actually not present at the very moment of his election. However, he left a message for Walter Adams to read. The introductory sentences give a brilliant example of his British sense of humour:

"I must speak to you from a distance through other lips; and you will doubtless observe that my recession from Stockholm has given my accent a displacement towards the West. [...] My uppermost feeling is a great responsibility to deserve the trust you have placed in me. We cannot foresee what may happen before we meet again in Zürich." (Eddington 1939c).

Why was he chosen by his peers to preside over the Union? At that point, the historian has no choice but to make some assumptions. No archive material has been preserved that could help understand the context and the motivations for Eddington's election. His welldocumented internationalism, though, may have been a determining factor (Eddington 1916; Stanley 2007, e.g.). He had both the moral authority and the willingness to assist the Union through the dark period of the war. At the end of the conflict and a few months 
after Eddington's death in November 1944, the director of the Harvard Observatory, Harlow Shapley, wrote:

"In the forthcoming problems on international scientific co-operation, immediately after the war, Eddington will be seriously missed. As president of the International Astronomical Union since 1938, he would have played a major role in the re-establishment of the activities and the spirit of good will in the various commissions of the Union. He was an ardent internationalist, and doubtless would have thought to round his career by taking part in the construction of a permanent peace" (Shapley 1945, p. 4).

What did Eddington do as president during the years of the Second World War? Unfortunately, it seems there is no available document to answer this. But for sure Eddington committed himself to international cooperation. Even before the state of war was officially declared he signed, along with a dozen other personalities, a manifesto broadcast in German by the BBC on 27 January 1939, and published the day after in English by the Times (Eddington 1939a). Later on, he helped some German astronomers to flee from Europe and be greeted in the USA. A couple of names may be mentioned. First, there was Hermann A. Brück. He had been living in Cambridge since 1937 with his wife and children thanks to Col. Frederick J.M. Stratton, who offered him an assistant position at the Solar Physics Observatory. Eddington soon intended to designate him as the first assistant of the Cambridge Observatory, but the war prevented this nomination to be confirmed. From May to September 1940, Brück was interned in England. Eddington then tried to arrange for his travel to Harvard, where he hoped Shapley would secure him a position for some time. The latter finally succeeded in his mission, apparently thanks to some financial arrangements between The New School (New York City) and the Harvard Observatory:

"I think I wrote you that the New School manages the appointment formally, but transfers Dr. Brück to the Harvard Observatory at once, where we shall make space for him and try to provide him with mind-filling enterprises... I hope that the financial details of the arrangements are kept as confidential as possible; and when the Brücks arrive here, I intend to ask them to keep the details strictly confidential, because otherwise it would be very embarrassing to me." $\dagger$

Presumably, Brück and his family stayed in America for a while, but no evidence has yet been found for the years 1941-1943. No later than 1943 Brück was back in Cambridge. After Eddington's death he unofficially took charge of the Observatory, until it was fused with the Solar Physics Observatory, the new entity being managed by Stratton. Brück then became Assistant Director of the Observatory (Stratton 1949, p. 23).

Another astronomer Eddington got to be concerned about was Herbert Jehle. Also a Quaker, Jehle had met Eddington during the year he had spent in Cambridge just after his PhD (1933-1934). Jehle was interned at the inception of World War II for about a year (1940-1941) in southwestern France (Merle d'Aubigné 1989, p. 72). Maurice Pryce wanted Jehle to be transferred to England and asked Dirac to act as an intermediary to contact Eddington. $\ddagger$ Although the details remain unknown, Jehle eventually went to Harvard Observatory at the end of 1941, where he taught until 1945. At that time, he prepared a homage to Eddington for the journal of the American Quakers. In his paper is quoted what appears to be a letter from Eddington dating back from 1940:

$\dagger$ Shapley to Eddington, 22 September 1940, Cambridge (Mass.), Harvard University Archives, Pusey Library, Harvard College Observatory Director's Records, UAV 630.22, Box 30.

$\ddagger$ Pryce to Dirac, 18 February 1940, Tallahassee, Florida State University, Special Collections Department, Paul A. M. Dirac Papers, Box 33, Folder 9. 
"I have found in the events of the last 12 months no ground for any weakening of my pacifist convictions. [...] The faith of a pacifist must, I think, continue to rest upon idealism or religious conviction rather than on any claim to political foresight" (Jehle 1945, p. 149).

\section{6. "The sky seems heavy with clouds"}

Let us conclude this brief recollection of episodes by quoting the last sentences of Eddington's Stockholm message:

"If in international politics the sky seems heavy with clouds, such a meeting as this at Stockholm is as when the Sun comes forth behind the clouds. Here we have formed and renewed bonds of friendship which will resist the forces of disruption" (Eddington 1939c).

And resist they shall.

\section{Discussion}

SODERBLOM: Eddington's election as IAU President was in 1938 and he votes his hopes to see people at the next GA "in 3 years". Was there a GA in 1943 ?

LAGUENS: Indeed, Eddington concluded his Stockholm message saying: "I tender to you my heartfelt thanks for this election and I look forward to meeting you all again at our reunion three years hence." Due to the war, obviously, the following GA did not take place in 1943 as initially planned. It occurred in 1948 in Zürich.

\section{References}

Adams, W. S. 1925, Proceedings of the National Academy of Sciences, 11, 382

Chandrasekhar, S. 1934, The Observatory, 57, 373

Chandrasekhar, S. 1935a, The Observatory, 58, p. 33

Chandrasekhar, S. 1935b, Monthly Notices of the Royal Astronomical Society, 95, 207

Chandrasekhar, S. 1935c, Monthly Notices of the Royal Astronomical Society, 95, 226

Chandrasekhar, S. 1979, American Journal of Physics, 47, 212

Dirac, P. A. M. 1977, in History of Twentieth Century Physics, C. Weiner (ed.) (New York: Academic Press), p. 109

Eddington, A. S. 1916, The Observatory, 39, 270

Eddington, A. S. 1926, The Internal Constitution of the Stars (Cambridge: Cambridge University Press)

Eddington, A. S. 1932a, The Observatory, 55, 301

Eddington, A. S. 1932b, Proc. Phys. Soc., 44, 1

Eddington, A. S. 1933, The Expanding Universe (Cambridge: Cambridge University Press)

Eddington, A. S. 1935a, in The Observatory, 58, p. 38

Eddington, A. S. 1935b, Monthly Notices of the Royal Astronomical Society, 95, 194

Eddington, A. S. 1936, in Transactions of the IAU, vol. 5 (London: Imperial College Bookstall), p. 238

Eddington, A. S. 1939a, The Times, 28 January 1939, 12

Eddington, A. S. 1939b, in Transactions of the IAU, vol. 6 (London: Imperial College Bookstall), p. 291

Eddington, A. S. 1939c, in Transactions of the IAU, vol. 6 (London: Imperial College Bookstall), p. 327

Holberg, J. 2010, Journal for the History of Astronomy, 11, 41

IAU 1922, Transactions of the IAU, vol. 1 (London: Imperial College Bookstall)

IAU 1925, Transactions of the IAU, vol. 2 (London: Imperial College Bookstall)

Jehle, H. 1945, The Friend [Philadelphia], 119, 149

Kennefick, D. 2009, Physics Today, 62, 37 
Kennefick, D. 2012, in Einstein and the Changing Worldviews of Physics, C. Lehner, J. Renn, M. Schemmel (eds.) (Boston: Birkhäuser), p. 201

Kragh, H. 2003, in The Cambridge History of Science, vol. 5: The Modern Physical and Mathematical Sciences, M. J. Nye (ed.) (Cambridge: Cambridge University Press), p. 522

Merle d'Aubigné, J. 1989, in J. Merle d'Aubigné, V. Mouchon, E. Fabre (eds.), Les Clandestins de Dieu, (Geneva, Labor et Fides), p. 61

NY Times 1925, The New York Times, 22 July 1925, 21

Shapley, H. 1945, Sky and Telescope, 4, 3

Stanley, M. 2007, Practical Mystic: Religion, Science, and A. S. Eddington (Chicago: Chicago University Press)

Stokley, J. 1932, The New York Times, 8 September 1932, 15

Stratton, F. J. M. 1949, The History of the Cambridge Observatories (Cambridge: Cambridge University Press) 